Ioana UNK

Faculty of Letters, Babeș-Bolyai University

Cluj-Napoca, Romania

ioana_unk@yahoo.com

\title{
THE AMERICAN DREAM. ACCULTURATION AND TRANSNATIONALISM
}

Recommended Citation: Unk, Ioana. "The American Dream. Acculturation and Transnationalism.” Metacritic Journal for Comparative Studies and Theory 4.2 (2018): https://doi.org/10.24193/mjcst.2018.6.10

\begin{abstract}
This paper aims to bring to the reader's attention three perspectives on the American dream, as seen through the eyes of the main characters in three novels: In America by Susan Sontag, Amerika. The Missing Person by Franz Kafka and the more recent Immigrant, Montana by Amitava Kumar. The perspectives are different - from Maryna's story of failure and success as an actress in America in 1876, to Karl Rossmann's escape from Europe and incomplete adventure in America, to AK's sexual experiences that mark the steps of his adaptation to the new country -, but they share similar acculturation and transnational strategies. Common themes such as the ethnic identity, the idea of a "portable homeland" will be investigated, in an attempt to outline the fluid contours of the elusive American dream.
\end{abstract}

Keywords: American dream, ethnic identity, acculturation, transnationalism

\section{Immigration and the American Dream}

This article tackles the concept of "the American dream" from an acculturation point of view and attempts to explain it, while defining its outlines from the perspective of the characters envisioning this dream. The "dreamers" are a group of Poles in search of freedom, a young man chased away from home, and an Indian student. I will take a closer look at the significance of the American dream for each character, while trying to identify the psychological changes they undergo when confronted with a new culture, 
the acculturation strategies they imply, the way they resolve the issue of their (new and old) ethnic identity, and the shape of their "portable homeland" (Kumar 58), i.e. the world within themselves, bearing the specific features of their motherland and the adoptive country.

The phrase "American dream” was first coined in 1931 by James Truslow Adams:

But there has been also the American dream, that dream of a land in which life should be better and richer and fuller for every man, with opportunity for each according to his ability or achievement. (...) It is not a dream of motor cars and high wages merely, but a dream of social order in which each man and each woman shall be able to attain to the fullest stature of which they are innately capable, and be recognized by others for what they are, regardless of the fortuitous circumstances of birth or position... (Adams 214215)

Adam's definition demarcates the construct vaguely, but scholars have tried to narrow it down ever since. When discussing Franklin's Autobiography, Lemay depicts it as an embodiment of the American dream, as a multifaceted expression of economic success, "the rise from impotence to importance, from dependence to independence, from helplessness to power" (24), an idea that appeals to basic human needs, an archetype for power and fame, an individualistic message - "the world can be affected and changed by individuals" (25) -, the basic human belief in the free will, as opposed to determinism, supported by a "philosophy of hope, even of optimism" (30).

If the initial concept of the American dream was connected to the New World and to economic opportunities, the meaning of the phrase was enriched after World War II, with the access to university studies (Williams 162), but in many cases, America and the American dream is "an open mental construction rather than a demarcated physical space" (Hawthorne 187), as it appears in Emerson's writings. The American dream as cognitive image is forever transforming and corresponds to a deep human need for betterment and refinement, the key to its accomplishment being the necessity of belief (Lemay 26). Ultimately, the American dream is "about beginnings, continually new beginnings" (Green 179, qtd. in Hawthorne 217). 
In many respects, the American Dream has been deeply rooted in the concept of a journey - the journey to a new country, the journey across generations, and of course, the journey within one's life. It is about motion and progress, it is about optimism, and it is about finding success and fulfilment along the way (Rank et al. 2).

As such, the idea of the American dream is inherently associated with the migration process and its two counterparts: emigration - the process of leaving one's native country - and immigration - the process of becoming part of a new country and, thus adhering to new linguistic and cultural features and values. Even though the agent undergoing the two processes is one and the same person, the shift in perspective that is required for the use of the two terms - emigration and immigration - requires a psychological and adaptive metamorphosis that takes place within a person. The emigrant is the person leaving something behind, who experiences a rupture - be it geographical, cultural or psychological -, who differentiates herself from her compatriots and experiences doubt and uncertainty. When she reaches the new country, she becomes an immigrant, starting to partially share the new cultural values of the receiving country, but still not fully belonging to her adoptive country. Her allegiance is divided between her native and her adoptive country, and this situation often results in a conflicting self.

Migration - comprising both emigration and immigration - is a strenuous enterprise, a perpetual learning experience and a constant negotiation of one's personal and receiving cultural values. Among the challenges that immigrants face when coming in contact with a new country and environment, Lansford et al. (3) indicate the infliction on one's social identity and self-image, communication and behavioural issues, demographic, social, economic and legal changes, all of these being a part of the assimilation process that entails the embrace of the new culture and new way of living. The psychological accommodation to the receiving culture, also known as acculturation - i.e. "a process of cultural and psychological change in cultural groups and families, and individuals following intercultural contact" (Berry, "Acculturation" 69; ch. 4) - also raises the issue of transnationalism and what it actually means in the larger context of a 
country built on transnationalism. Is the term "transnationalism" adequate to define the melting pot or is it synonymous with the notion of American dream?

The process by which immigrants become a part of the receiving country has been defined as assimilation, but, as Pedraza justly points out, "'Assimilation' meant to become alike - but like whom?" (419). Assimilation implies a passive acceptance from the immigrants of the new culture and habits of their adoptive country, and an implicit abandonment of their old cultural selves, which is rarely the case. Instead, "they develop new bicultural identities" (423) that are able to blend together the different cultural values of the two countries. Therefore, transculturalism and transnationalism are better fit to define the adjustment process of the immigrants.

Discussing the differences between the notions "immigrant" and "migrant", Schiller et al. associate the idea of "immigrant" with "images of permanent rupture, of the uprooted, the abandonment of old patterns and the painful learning of a new language and culture" (1). But such a grim image does not entirely depict the immigrant experience, so the authors plead in favour of using the concepts "transnationalism" to define the migration experience and "transmigrants" instead of "immigrants". This formal preference speaks volumes about the socio-cultural links that migrants establish between their country of origin and their receiving country.

At the intersection of cultural groups and individuals representing other cultures, different acculturation strategies emerge, their choice being influenced to a large degree by one's reasons for migration. One of the most common strategies is the integration, understood as valuing one's cultural heritage, but, at the same time, trying to integrate oneself into the receiving society. When members of the minority groups do not wish to preserve their cultural values and seek to adopt the cultural values of the dominant ethnocultural group, assimilation takes place. At the opposite end, we have the separation that occurs when an individual's preference for her original culture brings about the avoidance of the interaction with the others, followed by marginalisation, defined as a lack of interest for one's own culture, as well as for the culture of the dominant group, in many cases as a result of exclusion or discrimination (Berry, "Acculturation" 72; ch. 4). Acculturation, as a dynamic construct, involves the "processes by which different cultural groups adapt to one another" (Brown and Zagefka 178 
131), and this definition borders on the idea of transculturalism.

Psychological acculturation, i.e. the changes that an individual experiences under the influence of the external, dominant culture and the non-dominant culture which she represents (Berry, "Acculturation" 70; ch. 4), announces the birth of an inner country that combines the cultural elements of the mother country and the cultural standards of the adoptive country. This is the solution found by the divided self, a division often deepened by the change of one's name that occurs during the acculturation process.

To deal with this duality of belongingness, the migrant creates a comfortable land within, where the duality is not conflicting and the cultural values and habits of the two countries (the motherland and the receiving country) can coexist in harmony. This psychological locus has also been defined as a "type of conscience", as a "home away from home" or the "here and there" (Vertovec 450) that does not correspond to a geographical place.

A more pessimistic take on this bicultural inner locus is depicted by the theory of the "marginal man" (Park 881), a man torn between conflicting cultural tendencies and by his desire to live in two diverse cultural groups. If this situation persists, then it can become a changed personality type, often resulting in a broken individual.

Discussing these idealised communities as a psychological product of the immigration process, Waldinger and Fitzgerald draw attention to the literal meaning of "trans" (i.e. beyond), suggesting that transnationalism can be conceived as one's attempt to go beyond any connections to one's country of origin or ethnic group (1178).

Another issue deeply affected by the migration experience is the ethnic identity. Erik Erikson defines identity as a process that occurs in the core of the individual and, at the same time, in the core of the community culture. This definition suggests an intermingling of inner and outer forces that shape one's personality, and also the need to balance the sense of belonging to a culture and ethnic group, which forms the ethnic identity (Phinney and Ong 52; ch. 3) that the migrant brings from her native country, and the sense of belonging to the receiving country, that is on the verge of development. Psychologists identify three stages in the process of ethnic identity development: a first unexamined stage, characterised by almost a lack of ethnic identity or by an expression of ethnic identity as a mere mimicking of other's identity; moratorium, a second stage 
that is characterised by ethnic exploration; and the third stage of achievement of the ethnic identity, in which exploration is accompanied by commitment (52). This sense of ethnic identity reaches the mature stage in young adulthood, but in the case of migrants, its development continues into the first years of the migration experience, as they start by mimicking the common behaviour of the receiving country, continue by exploring the ethnic identity of the newly found group, before they are able to commit to the new values.

If we were to define the immigrant experience in terms of both acculturation and transnationalism, the two concepts would not exclude one another, but they would be part of a continuum, where the acculturation experience would be the first one to occur, followed closely by a transcultural phase, specific to transnationalism. Going through these phases corresponds to an inner psychological change, from immigrant, to migrant and to transnational citizen. What is also interesting to mention is that different acculturation strategies can be used by one and the same individual; these strategies can follow one another, corresponding to different stages in a migrant's life. In the acculturation phase, the impact of the dominant culture is more evident; the migrant is challenged to deal with the new cultural values, while the cultural values of her motherland are used as comparison resources. Transnationalism, on the other hand, rules out the predominance of one set of values over the other and brings about a cultural balance.

Citing Teggart's theory, Park describes the migration process as a very dynamic enterprise: upon impact with a new civilization, habits and customs are broken, new energies are released, and this equates emancipation or even enlightenment. "The individual is free for new adventures, but he is more or less without direction and control" (887). This inner chaos ends eventually with a reintegration of the migrant into the new society, and the benefits of the reintegration are evident: the migrant has become a cosmopolitan. "He learns to look upon the world in which he was born and bred with something of the detachment of a stranger. He acquires, in short, an intellectual bias" (888). Park's depiction of the migration process bears a close resemblance to the migration sequence indicated above: acculturation, characterised by adventure, confusion and also lack of control, followed by transnationalism, as cultural 180 
equilibrium and a detached perspective on the motherland.

\section{Susan Sontag and the Experience of the Group}

In America tells the migration story of a famous Polish actress, Maryna Załężowska, her husband, Bogdan Dembowski, her son, Piotr, the journalist and writer, Ryszard, and a small group of friends. The migration of the group starts as a tribe-like experience, similar to the ones that created the history of Europe (Park 886), but it gradually turns into individual endeavours. The initiative belongs to Maryna, the self-appointed leader of the group, and the others follow her without any apparent hesitations, but after a time spent in California, where the Polish group experiences the farm life, different aspirations surface and the group splits, each member following their own version of the American dream: Julian and Wanda return to Poland, without being able to improve their marriage, Danuta and Cyprian join Edenica, a vegetarian, Eden-inspired religious cult, Ryszard decides to dedicate his life to writing, and Maryna goes back to theatre and acting. The core of this separation lies precisely in the different reasons that determine the group members to move to America, and that act as triggers for their future development. The list of reasons is not exhaustive, but it shows multiple facets of the American dream:

“Because she's my wife, and I must take care of her. Because I can show my brother that I'm a practical man, a virile son of the land, not just a lover of theatre and the editor of a patriotic newspaper that was quickly shut down by the authorities. Because I can't bear always being followed by the police."

"Because I am curious, that's my profession, it's what a journalist should be, because I want to travel, because I am in love with her, because I am young, because I love this country, because I need to escape this country, because I love to hunt, because Nina says she is pregnant and expects me to marry her, because I've read so many books about it, Fennimore Cooper and Mayne Reid and the rest, because I intend to write a great many books, because..."

"Because she's my mother and she promised me she would take me to the Centennial Exposition, whatever that is."

"Because I, a simple girl, am to be her maid. Because, out of all the other candidates at 
the orphanage, all prettier and more skilled at cooking and sewing, she chose me.”

"Because that's where the future is being born."

"Because my husband wants to go."

“Because maybe I can’t be just Polish, even there, but I won’t be only a Jew.”

"Because I want to live in a free country."

"Because life there will be better for the children."

"Because it's an adventure."

"Because people should live in harmony (...)"

“(...) America is meant to mean everything” (Sontag 90-91).

Maryna's hesitation to express her expectancies about her adoptive country indicates an identity crisis that is only deepened by the American adventure. She is in search of a new way of living, carrying the huge burden of her former success as an actress, aware that she cannot discard it entirely - “(...) the past is the biggest country of all” (Sontag 23).

Sontag's characters that succeed in America employ a doubling strategy, which consists in splitting one's personality, one's self, to accommodate the two worlds that constitute every migrant's inner world:

Like most writers who are intelligent, Ryszard had long since accustomed himself to being actually two people. One was a warmhearted, anxious man, rather boyish for his twenty-five years, while the other one... in the other one, detached, reckless, manipulative, flourished the temperament of someone much older (Sontag 110).

When describing the Americans, Ryszard refers to two distinct selves that coexist in every person; while one self is living, the other one is just gazing at its active self. And while, for the "fresh-off-the-boat" immigrants, this personality schism is a painful attempt at life in two distinct worlds, it is also a first sign of their acculturation, the first indication that they are on the verge of becoming Americans. And, indeed, only those who are able to live with this inner division succeed: “Two Ryszards. Two Bogdans. (...) And two Marynas" (Sontag 206).

For Sontag's characters, America is the perfect embodiment of hope: "For more 182 
than fifty years Europeans have been saying, if it doesn't work, we can always go to America. (...) America is supposed to repair the European scale of injury or simply make one forget what one wanted, to substitute other desires" (Sontag 209). America is no longer a geographical destination, it is a universal, injustice-free, amnesia-inducing Nirvana that, when attained, has to be replaced by another, even greater dream, so that life can be meaningful again. When our migrants reach America and their dream is fulfilled, another ideal arises, and the American dream becomes the Californian paradise dream: "Doesn't it seem very American (...) that America has its America, its better destination where everyone dreams of going?" (120).

As Haslam points out, California holds a special place in America; it remains "terra incognita, a place that escaped domination by the Old World" (132), in the sense of a "spiritual frontier" (133), a land of promise and possibility that goes a step forward toward human betterment. As alternative to the American dream, the California that immigrants dream about does not even have to be real, it can be a "Fantasy California: the boundary where time and space merge, where expectation and realization blur" (141). For Sontag's migrants, the Californian dream turns out to be just a mirage and the gap between their expectation and reality is never filled.

Maryna's destiny in America exemplifies best the migration phases that are characteristic of most immigrants: acculturation, with its two strategies, assimilation and integration, followed by transnationalism. A first attempt at acculturation is made by Maryna in the assimilation stage, when the whole group that she is leading tries to get accustomed to the American farm life, while desperately trying to forget about their Polish life style. Despite the efforts of all members to acquire the American ways, assimilation does not seem to work, and when Maryna realises that, the group disintegrates. What started out as a tribe migration becomes an individual experience. The farm episode gives birth to another Maryna - the farmer Maryna - a bold, enterprising woman who wants to cut all ties with her old life. But this self-alienation is destructive and the actress has to recognise that she cannot deny her other roles.

A second phase in Maryna's migration life is the one corresponding to the integration strategy, when the actress uses her cultural heritage to adjust to the American life. It is probably the most significant stage in her life, as it resets her on the 
acting path and redefines her life in terms of acting, being on stage, being admired and adored. This is the moment in her life when she changes her name, upon suggestion of a theatre director and takes over the stage name of Marina Zalenska. The new name offers her a new identity in the new world, while allowing her to do what she knows best, i.e. to act.

Maryna's immigration success is determined, in part, by what is called "cognitive migration" (Koikkalainen and Kyle 750), a process that occurs before the actual migration and consists of a mental exercise of imagination that allows one to imagine oneself inhabiting a different country. This predecisional individual mindset plays an important role in choosing one's future destination, in setting a certain level of expectations, and in adjusting better to the new conditions. In this sense, Maryna's decision is the result of her reaching a mental threshold regarding her adoptive country, as well as the group that she wants to bring along on this journey.

Maryna conquers the English language, masters the American accent, becomes Marina and acquires a new identity. Nevertheless, Maryna's moment of achieving a new ethnic identity is a bitter one, because she recognises and assumes the constant sorrow of her new condition: "The American is someone who is always leaving everything behind. And the void this makes in his soul is a matter of astonishment to him, too" (Sontag 206).

What differentiates Sontag's novel from the other two discussed literary works is the female perspective on the migration experience. Sontag challenges the traditional gender roles showing that women can be more than passive participants to such adventures, that they can initiate and lead them, and by doing this, she contradicts the "archetypal American story", in which the female is "an object in his story" (Graulich 187).

\section{Kafka's Amerika or the Experience of The Missing Person}

The reason for Karl's coming to America is made obvious from the first sentence of the novel: "As he entered New York on the now slow-moving ship, Karl Rossmann, a seventeen-year-old youth who had been sent to America by his poor parents because a servant girl had seduced him and borne a child by him, saw the Statue of Liberty (...)” 184 
(Kafka 3). This phrase summons up everything there is to know about Karl, his life in Europe, and the reasons for his forced immigration. His parents' shame and his unconscious guilt will follow him throughout the entire novel as the mark of the immigrant.

Upon his arrival in New York, Karl's identity is challenged for the first time, as he has to produce a proof of identity: "Karl rummaged through his secret pocket, which he had no hesitation in showing to these people, took out his passport, and rather than saying a few words by way of introduction, simply laid it down open on the table" (Kafka 13). This is the moment that establishes his new identity, i.e. that of an American immigrant, an identity that will be reiterated many times: in several instances in the novel, he reaches for his passport and is asked to present some kind of documentation to prove his identity.

The meeting with his uncle Jakob is symbolic of Karl's acculturation process, as it lays out the context and the reader's expectations. The uncle discloses the details of his own acculturation process: "I have lived completely cut off from my European relatives for reasons that are, first, beside the point and, second, too painful to disclose" (Kafka 24). This depiction reflects the acculturation strategy selected by, or imposed on uncle Jakob, i.e. that of assimilation, consisting in an intentional acceptance of the American customs that prove to be successful for Karl's uncle.

Karl's trunk is of particular value to him and it is one of the most contested items during his adventures in America. The trunk gets lost on several occasions, then reappears and Karl is most concerned with finding a safe place where he could store his trunk ("His trunk had been put back in order again and was now probably more secure than it had been in a long time”, Kafka 119). The trunk stands for his European heritage, with his dated manners and excessive politeness, and his European guilt.

The trunk is the most precious thing he has upon his arrival in New York, the only thing that comforts him after his uncle decides to part with him, the reason for his separation from his fellow travellers, Robinson and Delamarche, when they attempt to steal the trunk: "On first opening the trunk, Karl was horrified. All those hours during the voyage he had spent arranging and rearranging the trunk, whereas now everything had been stuffed in so wildly that the lid sprang open as he released the lock" (Kafka 
86). Due to the incompleteness of the novel, we do not know what happens to the trunk in the end; its last mention is connected to Hotel Occidental, where Karl works for a while as an elevator boy, but it is safe to assume that the moment when Karl loses track of his trunk is the moment when his ties with Europe are cut and when his acculturation process enters the assimilation phase. Losing the trunk, which starts with losing or giving away items of its content, is a symbolic gesture by which Karl tries to erase his guilt. Karl Rossmann's American dream appears, at first, not to be his own dream; just as his migration to America was decided by his shamed parents, his dream of America is first imposed by his uncle, who wants to train him for a career in business, then he is sent to San Francisco by Mr. Green, his uncle's emissary, only to change his destination to Butterford, upon the suggestion of two vagrants, Delamarche and Robinson; he is then hired as an elevator boy, quickly fired and forced into working as a servant for Brunelda, Delamarche's girlfriend. The dream is unconscious and implicit, even if the character utters it only towards the end of the novel: he wants to survive; he needs to survive and to discard the guilt. Only when he is hired by an acting company that welcomes everyone does he starts to pursue his own American dream: "I wanted to become an engineer" (Kafka 281). He changes his name to "Negro", apparently on a whim or because of lack of inspiration, and starts to work as a technician, which is suggested to be a first step toward his future career. This moment marks the end of Karl Rossmann's assimilation period and the commencement of his next stage of acculturation, i.e. that of integration: by changing his name, he seems to want to sever the connection to his older self, but by remembering one of his old European dreams, i.e. that of becoming an engineer, he restores the balance between the cultural values of his motherland and those of the adoptive country.

Shortly after his arrival in America, Karl recognises that the issue of ethnic identity is problematic for every immigrant: "Indeed, the first days of a European in America could certainly be likened to a birth (...)" (Kafka 36). His period of lack of identity is brief, because he quickly enters the moratorium phase, where he watches closely and tries to mimic the ethnic identity of the locals. We do not witness his reaching a full achievement of an ethnic identity, but the moment when he starts his integration brings him closer to that identity. 
Karl's American experience raises the issue of the "Myth of America" (Mogen 22), a concept closely related to the American dream, but that implies "falsehood and illusion, commonly held misconceptions" (22), "ambivalence and ambiguity" (23). The basic constitutive elements of the Myth are the setting - "opposition between an Old World («civilization») and a New World” (24), the presence of a hero who connects the two worlds and the narrative - "some version of failed or achieved metamorphosis" (24). The Myth of America is nonetheless a variation of the "universal monomyth" (26), but even as such, it "emphasizes the possibility of rebirth, of exploring the limits of freedom" (26). Despite the fact that Karl's migration is imposed by his family, his American experience is a story of escapism and transformation. He does not start his transformation of his own free will, but the experiences he goes through form a connection between the two worlds. The lack of an ending for the novel prevents us from knowing if it was the American dream or the Myth of America that ultimately defined his adventure.

\section{Immigrant, Montana and the Portable Homeland}

Immigrant, Montana, by Amitava Kumar is a confession novel about the young Kailash, also called AK, an Indian coming to study in the US. For Kailash, the first facet of the American dream comes in the form of the opportunity to study in the States. The other aspects unfold with every love story that he experiences himself, or that he learns about, and that influences his acculturation. It is through these stories that Kailash discovers the romantic America, the academic America, the adventurous America.

AK's first brief romantic relationship with Jennifer marks his initiation into the basics of American life, as she introduces him to sex, new food and new music. Although AK is grateful for this first experience, he is not ready to settle for this first glimpse into the American dream and he continues to search for his own terra incognita:

I didn't want anything more at that time. There was an imbalance in our histories. I felt she had lived a full life and I hadn't; I had only begun to experience life, which is to say, sexual life. (...) Here, just a few months into my stay in America, I was finally leading a fuller experience. I understood that this newness couldn't be shared with those I had left 
behind (Kumar 38).

After the initiation, the love story with Nina refines AK's sexual experiences and takes his knowledge of America and the American dream even further, by learning how to master sex and language:

"Tongues untied, Your Honor. The language of liberation that came through language itself. And then the liberation of the body" (Kumar 143).

"Your Honor, I have entered the body of America. I have spoken filth in the ear of one of your fair citizens when I was inside her. Your Honor, this was something new for me" (147).

"But I was also, Your Honor, exploring language. I was the poet of my own sexual liberation" (150).

The third romance with Cai Yan, an immigrant herself, offers AK the opportunity to see himself in a mirror; in many ways Cai Yan is similar to him, her struggles are his own, but in most ways she stands for cultural values that are unknown to AK: "I stood, a stranger, a supplicant, a homeless alien, at the gates of an implacable continent. I saw her as if at a huge distance, standing alone at the end of a long road" (Kumar 223).

Kailash does not experience the name change as something painful. He recognises the humour of the situation - he is first called "Kalashnikov" by a German friend, and then AK-47, this leading to the shortened AK or 47 - and accepts the amusement of his fellow students as part of his acculturation process.

The epilogue of the novel gives the reader a chance to meet the middle-aged AK, reminiscing about his youth and describing his experience of becoming a US citizen. On his way home from the naturalisation ceremony, AK receives a fine for driving too fast, which he interprets as a punishment for his immigration sins, for betraying his native country and becoming the citizen of another state, and what is supposed to be a gain feels like a loss: "But I only felt like a man without a country and tears came to my eyes" (Kumar 290). This feeling is an expression of a deeper reality. Like most migrants, AK has multiple attempts at achieving a feeling of belongingness - to a country, to a culture, to a person -, only to find that his situation can be best defined by the in-between-ness: 188 
“(...) It seems to me that Mr. In-Between is precisely where we all live now.” (302), says Kailash, citing Davis Shields in Reality Hunger.

Written in the first person, Immigrant, Montana reads like a confession of guilt: the guilt of the migrant abandoning his motherland, his parents, his mother tongue. The guilt is so pervasive and deeply embedded in his way of relating to the outer world, that AK expresses his emotions through an imaginary dialogue with a judge:

The truth, Your Honor, is that the immigrant feels at home in guilt. How could I deny guilt and wrongdoing? I'm not talking only of the lies I have uttered when I applied for the visa, no, I'm aware at this moment only of the guilt of having abandoned my parents. A slippery rope, this. My father, my mother, my motherland, my mother tongue (Kumar 19).

This pervasive feeling of guilt results in a personality schism:

For so many years, the idea of writing has meant recognizing and even addressing a division in my life: the gap between India, the land of my birth, and the United States, where I arrived as a young adult. If and when I imagine an audience for my writing, it is also a divided one. But the two places are connected... (Kumar 5).

The feeling of guilt is doubled by a feeling of constant fear that is not caused by any immediate danger, but by a constant awareness of the reality: "I was safe in my apartment, and there was no immediate peril of any sort, but I was overcome by a feeling that took root then and has never left me, the feeling that in this land that was someone else's country, I did not have a place to stand" (Kumar 39). Kailash realises that there is no logical explanation for this guilt, and that it is rooted in the immigration experience itself that creates the problem, but, at the same time, offers the cure. In this realisation lies the key to his migration story and his passage from acculturation to transnationalism:

As far as I was concerned, immigration was the original sin. Someone owed me something. This half-expressed thought had found a home in my heart. It provided me 
an exaggerated sense of identity, and granted me permission to do anything I wanted. I'm not trying to justify anything; I only intend to explain (Kumar 169).

The transcultural solution that Kailash-AK finds for his transnational experience is the "portable homeland, the things that migrants carry with them" (Kumar 58), be them material things or just memories or cultural values. It is the same in-between country that he refers to years later and that shows that this strategy proved to be successful for him.

$\mathrm{AK}$ is a transnational collector of love stories, sexual experiences, cultural information, mundane facts. His continuous references to his home country and to his childhood experiences, but also the detachment from his native environment ("I understood that this newness couldn't be shared with those I had left behind", Kumar 38; "I had never loved India as much as I do now, when I was so far away" 31) that he acquires soon after his first sexual experience define his transcultural-transnational destiny. His acculturation phase is brief and the only strategy that he uses is the integration, because he attains a "global identity" (187). AK is subjected to a multidimensional process of cultural learning that results in psychological changes, called "behavioural shifts" (Berry, "A Psychology" 621). He experiences a gradual learning or improvement of language, an initiation in the sexual practices and the way he perceives intercourse, a change in his daily conversation topics. This process of cultural alteration underlines the strong connection between one's cultural values and one's language and attests to the way a new culture is acquired by modifying one's use of language.

\section{Overlapping Circles}

The migrant story is everlasting. It is the same story, lived by different individuals, carrying different heritages and creating different perspectives on their adoptive country, but with a significant number of overlapping areas. Primarily, they all experience the uprooting as more or less traumatic, and they all find coping strategies, depending on their personality, experiences and cultural values.

Sontag's and Kafka's characters experience immigration in what we would call 190 
today technologically challenged times, so their failure or tardiness to reach transnationalism can find a justification in the lack of technological development. Kumar's character, on the other hand, finds the transnational strategy as most adaptive, due to the rapid access to the desired information, but also due to the academic environment that offers him enough stimulation and also opportunities to create links between the American and the Indian cultures.

For both Karl Rossmann and AK, the immigration experience is connected to a deep feeling of guilt that they are not able to overcome. AK is aware of his guilt and perceives many of the events he is involved in as forms of punishment for his guilt, whereas for Karl Rossmann - as for most of Kafka's characters - guilt is an inherent condition, to which immigration only adds on.

Maryna and Karl find their new ethnic identities in the acting environment. For Maryna, the new role of Marina means accomplishing her American dream, while for Karl Rossmann working for a theatre company reveals long-forgotten dreams. Just like the numerous roles that an actor can perform in a lifetime, America has many opportunities to offer to its "dreamers".

All three characters undergo a name change and this experience is the most symbolic for the life of a migrant. While Maryna protests slightly against the prospect of having to change her name, Karl Rossmann and AK seem to accept this change as something natural, but nevertheless, self-defining. To change someone's name means to reinvent and to rediscover them and their true essence, because: "Names are the bridges to people's castles of existence. It is via them that others, friends and foes alike, can find a way to tiptoe in. To learn someone's name is to capture half of her existence, the rest is a matter of pieces and details" (Shafak 22).

\section{References}

Adams, James Truslow. Epic of America. Little, Brown, and Co., 1931.

Berry, John W. “Acculturation Strategies and Adaptation." Immigrant Families in Contemporary Society. Edited by Lansford, Jennifer E., Deater-Deckard, Kirby, Bornstein, and Marc H. The Guilford Press, 2007: 69-82.

Berry, John W. "A Psychology of Immigration.” Journal of Social Issues, vol. 7, no. 3, 
2001: 615-631.

Brown, Rupert, and Zagefka, Hanna. "The Dynamics of Acculturation: An Intergroup Perspective.” Advances in Experimental Social Psychology, vol. 44, 2011, pp. 129 184,https://pdfs.semanticscholar.org/bodf/bda32ea1f271b7c3af5605a371da3139 9b65.pdf. Accessed 13 Oct. 2018.

Graulich, Melody. “'O Beauty for Spacious Guys': An Essay on the 'Legitimate Inclinations of the Sexes'." The Frontier Experience and the American Dream. Essays on American Literature. Edited by Morgan, David, Busby, Mark, and Bryant, Paul. Texas A\&M University Press, 1989: 186-201.

Haslam, Gerald. "Golden State: A Demanding Paradise, an Enduring Frontier." The Frontier Experience and the American Dream. Essays on American Literature, edited by Morgan, David, Busby, Mark, and Bryant, Paul. Texas A\&M University Press, 1989: 132-145.

Hawthorne, Julian. "Emerson as an American." The American Dream. Edited by Bloom, Harold. Infobase Publishing, 2009: 187-202.

Kafka, Franz. Amerika: The Missing Person. Schocken Books, 2008.

Koikkalainen, Saara, and Kyle David. "Imagining mobility: the prospective cognition question in migration research." Journal of Ethnic and Migration Studies, vol. 42, no. 5, 2016: 459-776. doi: 10.1080/1369183X.2015.1111133.

Kumar, Amitava. Immigrant, Montana. Faber \& Faber, 2017.

Lansford, Jennifer E., et al., "Introduction. Immigrant Families in Contemporary Society." Immigrant Families in Contemporary Society. Edited by Lansford, Jennifer E., Deater-Deckard, Kirby, Bornstein, and Marc H. The Guilford Press, 2007: 1-6.

Lemay, J.A. Leo. "Franklin's Autobiography and the American Dream". The American Dream. Edited by Bloom, Harold, Infobase Publishing, 2009: 21-36.

Mogen, David. "The Frontier Archetype and the Myth of America: Patterns That Shape the American Dream." The Frontier Experience and the American Dream. Essays on American Literature, edited by Morgan, David, Busby, Mark, and Bryant, Paul. Texas A\&M University Press, 1989: 15-30.

Park, Robert E. "Human Migration and the Marginal Man." The American Journal of 192 
Sociology, vol. XXXIII, no. 6, May 1928: 881-893, http://www.suz.uzh.ch/dam/jcr:fffffff-df42-7cac-0ooo oo0032ce5aod/Park Marginal Man.pdf. Accessed 17 Oct. 2018.

Pedraza, Silvia. "Assimilation or Transnationalism? Conceptual Models of the Immigrant Experience in America." Cuba in Transition. 2005: 419-428. https://ascecuba.org/c/wp-content/uploads/2014/o9/v15-pedraza.pdf. Accessed 16 Oct. 2018.

Phinney, Jean S, and Ong, Anthony D. "Ethnic Identity Development in Immigrant Families." Immigrant Families in Contemporary Society. Edited by Lansford, Jennifer E., Deater-Deckard, Kirby, Bornstein, and Marc H. The Guilford Press, 2007: 51-68.

Rank, Mark Robert, et al. Chasing the American Dream. Understanding What Shapes Our Fortunes. Oxford University Press, 2014.

Waldinger, Roger, Fitzgerald, David. "Transnationalism in Question." American Journal of Sociology, vol. 109, no. 5, 2004: 1117-1195. https://cloudfront.escholarship.org/dist/prd/content/qt2bk9034r/qt2bk9034r.p df. Accessed 13 Oct. 2018.

Schiller, Nina Glick, et al. "Transnationalism. A New Analytic Framework for Understanding Migration.” Annals New York Academy of Science, July 1992: 124.http://www.archivio.formazione.unimib.it/DATA/Insegnamenti/10_2246/m ateriale/glick\%20schiller\%20-\%201992.pdf. Accessed 13 Oct. 2018.

Shafak, Elif. The Saint of Incipient Insanities. Farrar, Straus and Giroux, 2004.

Sontag, Susan. In America. Picador USA, 2001.

Vertovec, Steven. "Conceiving and Researching Transnationalism." Ethnic and Racial Studies, vol. 22, no. 2, March 1999: 447-462, http://citeseerx.ist.psu.edu/viewdoc/download?doi=10.1.1.202.4125\&rep=rep1\& type $=$ pdf. Accessed 13 Oct. 2018.

Williams, Jeff. "Alternative Routes along the Road: Kerouac and the Multifaceted American Dream.” The American Dream. Edited by Bloom, Harold, Infobase Publishing, 2009: 161-169. 